Discussion Self-management and relevant knowledge are the important preventive factors of NCD prevention and there should be combined with the effective follow-up measure. However, this finding should be applied in large scale or in community.

\section{USING ETHNOGRAPHIC INTERVIEWS TO FACILITATE A PARTICIPATORY ERGONOMICS STUDY AMONG HOME- BASED MAPUCHE WEAVERS IN SOUTHERN CHILE}

${ }^{1} \mathrm{G}$ Gracia*, ${ }^{2} \mathrm{~A}$ Guzman, ${ }^{3} \mathrm{~L}$ Forst. ${ }^{1}$ University of Illinois at Chicago, Chicago, USA; ${ }^{2}$ MAPLE Micro Development, Temuco, Chile; ${ }^{3}$ University of Illinois At Chicago, Chicago, Illinois, USA

\subsection{6/oemed-2018-ICOHabstracts. 1422}

Introduction While there is extensive literature on ergonomic hazards related to weaving, research on implementing interventions is limited. The Mapuche represent Chile's largest indigenous population and weaving represents an important source of income for women. While home-based work allows for flexible scheduling, it can also lead to working long hours, difficulty balancing professional and domestic responsibilities and greater occupational health issues. Participatory approaches have proven successful in addressing occupational health problems, however, there is scant research related to home-based artisans.

Methods A convenience sample of 35 home-based Mapuche weavers in Southern Chile were recruited for the study. Of these, 10 participated in ethnographic interviews. Purposive sampling was used to obtain a representative sample across communities, identified health issues; workspace type; and years of weaving experience. Semi-structured interviews were conducted in the weavers' homes along with videos, photograph and written observations of the weaving workspaces. The interviews focused on workday organisation; weaving workspace; self-identified health issues, perceived causes and potential solutions to hazard prevention. Data were analysed using Atlas.ti.

Results Each interview yielded a 'day-in-the-life' visual. This graphic model helped facilitate discussions around time management, health issues, potential causes and treatment. In addition to weaving, participants identified farm work $(n=9)$, housework $(n=9)$, wool production $(n=7)$ and dyeing $(n=7)$ as tasks that caused health issues. Respondents identified weaving as the cause of eyestrain $(n=7)$, back $(n=6)$, shoulder $(n=5)$ and hand pain $(n=4)$. Interventions identified, implemented and currently being evaluated include: provision of eye exams, a kinesiologist workshop and provision of headlamps.

Conclusion This project demonstrates the importance of using ethnographic methods to strengthen participatory approaches to artisan occupational health. The data provided unique insight into the complex relationship between home-based work, health and sustainable interventions. This work yielded a culturally appropriate methodology that can be applied to other home-based artisans.

\section{WORK EQUIPMENT AND UNSAFE USE IN MICRO AND SMALL ENTERPRISES}

${ }^{1}$ Filip Pelgrims*, ${ }^{2}$ Hilde De Raeve, ${ }^{3}$ Marc Beurms. ${ }^{1}$ Product manager SME segment Group IDEWE, Leuven, Belgium; ${ }^{2} M D$ PhD Research department Group IDEWE, Leuven, Belgium; ${ }^{3}$ CIO and CFO Group IDEWE, Leuven, Belgium/Chairman of the dataforce of Belgian OSH services

10.1136/oemed-2018-ICOHabstracts. 1423
Aim The detection of unsafe handling with work equipment in small and micro enterprises.

Introduction A well elaborated occupational safety and health policy is crucial, yet, can micro and small scaled enterprises (MSE's) develop a good safety program, according working with workequipment?

Methods Idewe, a Belgian external service for prevention and protection at work, uses the online risk-assessment tool 'BRIE (i.e. Better Risk Inventarisation and Evaluation) to guide occupational health and safety experts during periodic company visits. BRIE risk-assessments were performed in a convenience sample of MSE's during the period 2015-2016. A selection of questions about safety handling $(n=6)$ was assessed. Examples are:

- Has the employer already made an inventory of the workingequipment?;

- Are there good safetyinstructions for all work equipments?;

- Have the employees been trained on safe use of work equipment?

Only the MSE's where all safety factors (work equipmentrelated) were scored, were included for analysis. Prevalences were calculated using frequencies.

Results Brie provides, 1/a list of important sector specific OSH issues (e.g. workequipment), 2/advice regarding good practices, legal information and preventive actions and 3) an evaluation of sector specific occupational risks. Data was available from 1950 MSE's. About 59\% of the companies, did not have an inventory of there workequipment. 53\% of the companies did not have any instruction for there working-equipment. Only $33 \%$ scored positive on training or education of there employees about safe use of their work equipment.

Discussion Brie risk-assessments reveal that assessments and policies regarding safe use of working equipment is non-existing in a significant number of MSE's. MSE's therefore need extra support, information, and advise.

\section{Thermal Factors}

\section{THE EFFECTIVENESS OF DAYTIME BATH AMONG NEW CONSCRIPTS IN A TRAINING UNIT FOR HEAT INJURY PREVENTION}

${ }^{1}$ Kathawoot Deepreecha*, ${ }^{2}$ Wittaya Seehabun, ${ }^{3}$ Boonterm Saengdidtha. ${ }^{1}$ Health Promotion and Preventive Medicine Division, Royal Thai Army Medical Department, Bangkok, Thailand; ${ }^{2}$ Third Medical Battalion, Third Infantry Division, Nakornratchasima, Thailand; ${ }^{3}$ Outpatient Department, Phramongkutklao Hospital, Bangkok, Thailand

\subsection{6/oemed-2018-ICOHabstracts. 1424}

Introduction Heat injury is a common illness among new conscripts during basic training course in Thailand and heat stroke is a major cause of death. There are a lot of methods to reduce the body temperature of conscripts to prevent heat injury. The conscripts are allowed to take a bath in the evening every day as regular bath during training. Daytime bath is one of the procedures. The objective of this study is to compare the effectiveness between daytime bath and regular bath for heat injury prevention among new conscripts in training unit.

Methods A quasi-experimental study was conducted in 93 new conscripts in training unit. The data of their body temperature before and after daytime bath in the time of 1200 and 0300 